\title{
The Faceless Patient and the Misled Psychiatric Resident: a Clinical Recollection
}

\author{
Claudio E. M. Banzato ${ }^{1}$
}

Received: 25 February 2020 / Accepted: 31 March 2020 / Published online: 28 April 2020

(C) Academic Psychiatry 2020

This case keeps coming back to my mind repeatedly, even though more than 30 years have passed since then. No other single case has taught me that much about how little we understand what actually takes place in a clinical encounter and the powerful effects of non-specific care. I was in my first year of the psychiatric residency (PGY1), spending my time at the psychiatric unit and the psychiatric emergency room of the university general hospital. The patient in question was an older man who lived alone. Nine years before, due to a very aggressive and infiltrating cancer in his palate, he had undergone a highly mutilating but life-saving surgery that took off most of his face. As he did not wear any prosthetics, his looks were quite disturbing. He was brought to the emergency room because he was very depressed in the last 3 months, staying in bed most of the time, losing weight, and saying that he would rather be dead. He had no previous psychiatric antecedents, and recurrence of the cancer was ruled out. He was diagnosed with severe melancholic depression and was hospitalized to be submitted to ECT. However, during his first night at the hospital, he presented a life-threatening heart arrhythmia and was transferred from the psychiatric to the internal medicine ward and was given anti-arrhythmia drugs. Though the heart condition was relatively controlled, he was no longer considered eligible for ECT treatment because of the risks of the anesthesia. Neither could he use the standard antidepressant drugs at the time, the tricyclics. So, the next morning I found a severely ill psychiatric patient under close monitoring in a clinical infirmary and limited resources to treat his depression.

Before I first met the patient, this is what I overheard from the hospital staff: "no wonder he was severely depressed longing for death, with a face like that anyone would feel the same"; "how could such an extreme surgery be performed, leaving the patient

Claudio E. M. Banzato

cbanzato@unicamp.br; claudio@lexxa.com.br

1 Medical School, University of Campinas (Unicamp), Campinas, SP, Brazil nearly faceless?"; "how on earth was the patient supposed to live like this?". The patient was fragile, spoke low, and presented himself as being beyond hope. Nevertheless, at the same time, he received me well and accepted the antidepressant pills I prescribed (under senior supervision), the MAO inhibitor tranylcypromine. Every morning I went to his bedside and stayed there talking to him for an hour, trying to learn more about him and his suffering. After a week, his general medical condition started to improve. In the second week, he became more talkative, and in the third, his mood was much better. The patient could not explain why he got so depressed, as he used to be a cheerful person who had always enjoyed life. Besides, he was immensely grateful to the bold and brave surgeon who took up the challenge, operated and cured him of cancer, something other doctors did not believe it could be done. I was delighted to see the patient recovering. Then, one morning, I was going over his prescription chart, and a nurse from the clinical ward told me, to my great surprise and dismay, "well, I do not know why you bother to keep prescribing this drug, the hospital ran out of tranylcypromine six months ago." The patient was taking several other drugs, and he could not know that precisely the antidepressant was missing. So, a perfect, natural, double-blind therapeutic trial had taken place. The response to treatment was excellent. But the question remained, to which treatment?

Let me suggest a counterfactual before we address the critical question above. Suppose the patient had taken the pills of tranylcypromine as prescribed. Would anyone even remotely think of the possibility that the patient responded to something else than the antidepressant drug? We strongly feel the need to explain our therapeutical failures, but we hardly ask ourselves about the determinants of the positive outcomes in each individual case. We simply assume that the treatment (whatever it may be) worked for the specific reason we believe it should have worked. The case presented here shows that it is not necessarily so.

The patient responded to the care, and this is the simple and plain truth (and yet also an inconvenient one). The care was delivered in a myriad of forms. For starters, he was stabilized 
from arrhythmia, and he was adequately renourished. He also received much attention from the staff and from the young psychiatric resident I once was, keen to get to know him and his circumstances better and to help him out of his melancholic state. It is not possible, I am afraid, to pinpoint the cause of his recovery.

To sum up, many people were proved wrong in their hasty judgments in this case. The patient was not depressed because of his mutilating surgery. For him, it was a life-saving surgery for which he had nothing less than gratitude. The alluring formula "if I were in his place, having undergone that surgery, I would be as depressed as he is" could not be more off the mark here. The ways I feel, apprehend things, value them, and operate in the world are not safe guides to the experience of others; on the contrary, they can easily prevent access to alterity. The resident thought (misled but with his mind at peace) he was effectively treating this severe case of depression with a powerful drug, which happened not to be available. The patient himself, who took several pills daily for clinical reasons, could not possibly suspect he was not receiving the pill I prescribed, but nonetheless obliged and recovered.
The patient was released from the hospital well and resumed his life. He was not followed for long in our outpatient clinic, so I do not know what happened to him thereafter. From my side, thenceforward, claims of specific effects of given treatments (irrespective of their nature) were always to be received with a grain of salt.

\section{Compliance with Ethical Standards}

Ethical Considerations (e.g., IRB information, consent process, if applicable) No patient consent could be obtained in regard to the clinical vignette presented, but information about the patient, seen more than 30 years ago, was kept to a minimum in order to preserve the due confidentiality.

Disclosures The author states that there is no conflict of interest.

Publisher's Note Springer Nature remains neutral with regard to jurisdictional claims in published maps and institutional affiliations. 